\title{
Rancang Bangun Grade Monitoring Assist pada D3K Caterpillar Berbasis Mikrokontroler sebagai Akurasi pada Pekerjaan Operator Dozer
}

\author{
Abdul Halim ${ }^{1 *}$, Mangkona ${ }^{2}$, Abdul Muis ${ }^{3}$, Irfan Andika Sakti ${ }^{4}$ \\ 1,2,3,4 Mechanical Engineering Department, Politeknik Negeri Samarinda \\ *Koresponden email: halim72@polnes.ac.id
}

Diterima: 15 September 2021

Disetujui: 3 November 2021

\begin{abstract}
In the process of construction work, operators need accuracy in the process of finishing land leveling works such as road \& highway building, land reclamation, large commercial, landfill installation, so as to increase productivity. Therefore, the purpose of this research is to manufacture and implement a ground leveling finishing tool using Arduino IDE software and Atmega 328 microcontroller on the Dozer D3K Caterpillar heavy equipment unit. The placement of a series of components from the Grade Monitoring Assist includes the ultrasonic sensor on the lift cylinder, gyro and accelerometer at the top center of the blade, as well as a display that displays the results of parameter readings. Connections between components in Grade Monitoring Assist are cables that integrate all installed components. The results of testing the movement of the blade up and down position to get an accuracy value of $97.30 \%$ and an error of $2.70 \%$. While the movement of the blade down position has an accuracy value of $96.50 \%$ and an error of $2.50 \%$. And Tests by moving the blade according to the implement movement angle at the maximum blade angle position (either side) with an average error value of $1.48^{\circ}$, cutting ditches (angle V) an average error value of $0.676^{\circ}$. Keywords: microcontroller, arduino, grade monitoring assist, operating dozer, catepillar D3K
\end{abstract}

\begin{abstract}
Abstrak
Dalam proses pekerjaan konstruksi, operator membutuhkan keakuratan pada proses pekerjaan finishing perataan tanah seperti road \& highway building, land reclamation, large comercial, landfill installation, sehingga dapat meningkatkan produktivitas. Tujuan penelitian ini adalah pembuatan dan pengimplementasian alat bantu finishing perataan tanah dengan sofware Arduino IDE dan mikrokontroler Atmega 328 pada unit alat berat Dozer D3K Caterpillar. Penempatan rangkaian komponen dari Grade Monitoring Assist ini diantaranya yaitu pada ultrasonic sensor pada bagian lift cylinder, gyro and accelerometer pada bagian atas tengah dari blade, serta display yang menampilkan hasil nilai pembacaan parameter. Penghubung antar komponen pada Grade Monitoring Assist digunakan kabel yang mengintegrasikan semua komponen yang dipasang. Hasil pengujian pergerakan posisi naik dan turun blade untuk mendapatkan nilai akurasi $97,30 \%$ dan error $2,70 \%$. Sedangkan pergerakan posisi turun blade nilai akurasi 96,50\% dan error 2,50\%. Dan Pengujian dengan mengerakkan blade sesuai sudut pergerakan implemen pada posisi blade maximum angle (either side) nilai error rata-rata $1,48^{\circ}$, cutting ditches (angle $V)$ nilai error rata-rata $0,676^{\circ}$.
\end{abstract}

Kata Kunci: mikrokontroler, arduino, grade monitoring assist, operator dozer, Catepillar D3K

\section{Pendahuluan}

Dalam pengoperasian dozer sebagian operator masih mengandalkan felling atau perkiraan berdasarkan pengalaman yang telah diperoleh. Dalam hal lain operator yang masih belum berpengalaman akan membutuhkan penyesuaian dalam pengoperasian dozer. Hal ini dapat menimbulkan masalah seperti downtime yang terjadi, serta cycle time yang kurang maksimal. Oleh karena itu, perlu adanya alat ukur yang dapat membantu melakukan pemantauan dalam pengoperasian dozer yang dikhususkan pada pekerjaan perataan pada tahap penyelesaian akhir untuk perataan permukaan. Proses finishing perataan dan penyebaran tanah merupakan hal memerlukan tingkat akurasi dan kecepatan dalam proses pekerjaannya. Hal ini menuntut adanya penggunaan teknologi yang diintegrasikan dengan unit alat berat khususnya pada unit dozer [1].

Berdasarkan informasi laporan dari PT Adimitra Baratama Nusantara (2018), bahwa dengan adanya penggunaan teknologi alat bantu perataan tanah yang dipasang pada unit mereka yang menggunakan teknologi SITECH, dapat mengefisienkan waktu dan mempermudah operator dalam melakukan pekerjaan [2]. Selain itu penggunaan alat bantu lain yang mulai diintegrasikan pada unit alat berat generasi terbaru 
yaitu Cat Accu Grade yang digunakan oleh Caterpillar [3], intelligent machine control yang digunakan oleh Komatsu dan smart grade yang digunakan John Deere [4][5][6][7].

Dari beberapa penggunaan teknologi yang dipasang pada unit alat berat model terbaru tersebut mengindikasikan monitoring pengoperasian berbasis teknologi perlu dilakukan. Oleh karena itu, pembuatan alat pemantauan perataan tanah unit dozer berbasis mikrokontroller Ardunino Atmega 328 dapat membantu untuk menunjang kinerja dari pengoperasian dozer. Alat yang dibuat semi permanen ini merupakan grade monitoring assist yang merupakan alat bantu pemantauan nilai parameter pergerakan implement dalam pengoperasian dozer, tidak untuk pengontrolan otomatis unit dozer.

Dari banyak penelitian penggunaan microcontroller arduino dan sistim sensor selalu dilakukan untuk melakukan sistim pengendalian dengan berbagai tujuan obyek, sebagai rujukan penulis dalam penelitian terdahulu adalah penelitian menggunakan dua sensor (accelerometer dan gyroscope) untuk mendapatkan pembacaan data yang stabil dan handal pada implementasi robot keseimbangan beroda dua [8][9][10], menggunakan giroskop untuk mengukur kecepatan sudut (rad/s) [11], pendeteksian pengendalian dengan menggunakan sensor ultrasonik [12][13][14]. Begitu pula penggunaan secara manual dalam mengendalikan pergerakan pesawat tanpa awak yang dikendalikan mikrokontroler dengan mengolah data-data gyroscope dan accelerator sensor untuk mengarahkan pesawat dari satu titik ke titik lain [15]. Inilah yang membuat penulis kemudian mencoba memanfaatkan mikrokontroler arduino dan kompenen pendukung lainnya seperti gyroscope dan accelerator sensor, ultrasonic sensor, plat reflector yang merupakan komponen utama dari alat grade monitoring assist. Tujuan penelitian ini adalah pembuatan dan pengimplementasian alat bantu finishing perataan tanah dengan sofware Arduino IDE dan mikrokontroler Atmega 328 pada unit alat berat Dozer D3K Caterpillar.

\section{Metode Penelitian}

Metode yang digunakan dalam pembuatan alat Grade Monitoring Assist ini berdasarkan studi literatur data yang diperoleh dari observasi langsung pada unit yang digunakan untuk mengaplikasikan alat ini. Setelah data dikumpulkan dan penempatan rancangan alat pada unit telah ditentukan barulah penulis melakukan riset untuk desain dari peletakan posisi alat yang akan ditempatkan serta bentuk rancangan dari alat Grade Monitoring Assist ini. Metode ini akan membantu penulis dalam melakukan pembuatan alat mulai dari awal sampai dengan alat ini dioperasikan sebagai alat bantu dalam pengoperasian dozer dalam hal perataan tanah. Untuk mengimplementasikan sistem alat parameter perataan tanah berbasis mikrokontroler ini beberapa tahap harus dilaksanakan. Gambar 1 memperlihatkan flow chart diagram yang merupakan tahapan yang dilakukan dalam perancangan program dan pembuatan alat, diawali dengan studi literatur untuk mencari sistem yang tepat untuk digunakan, sampai pada pengambilan keputusan apakah alat berfungsi sesuai dengan yang diinginkan atau tidak.
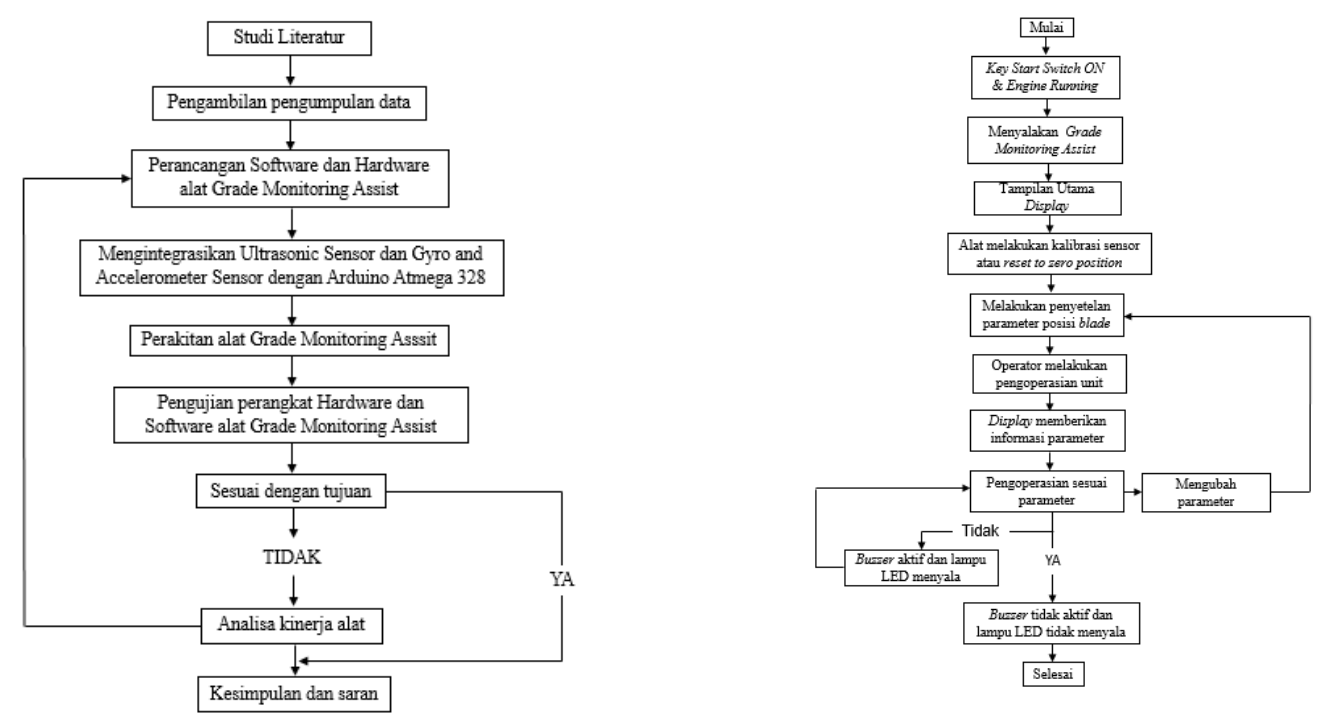

Gambar 1. Flow chart penelitian dan prodesure pengujian alat Grade Monitoring Assist Sumber: Dokumen pribadi, 2021 


\section{Prosedur Penelitian}

Metode pengumpulan data yang digunakan yaitu dengan melakukan pengukuran perbandingan antara peletakan dari alat yang akan dibuat dengan implemen unit yang akan digunakan sebagai parameter pembacaan. Hal ini dilakukan untuk menyamakan hasil pembacaan yang akan ditampilkan pada display. Pengukuran dilakukan pada cylinder lift, yaitu pengukuran untuk mengetahui panjang dari lift cylinder pada posisi blade normal. Kemudian dilanjutkan pengukuran panjang lift cylinder setiap blade dinaikkan atau diturunkan $10 \mathrm{~cm}$ hingga menemukan posisi maksimum exstand dan retrack pada lift cylinder.

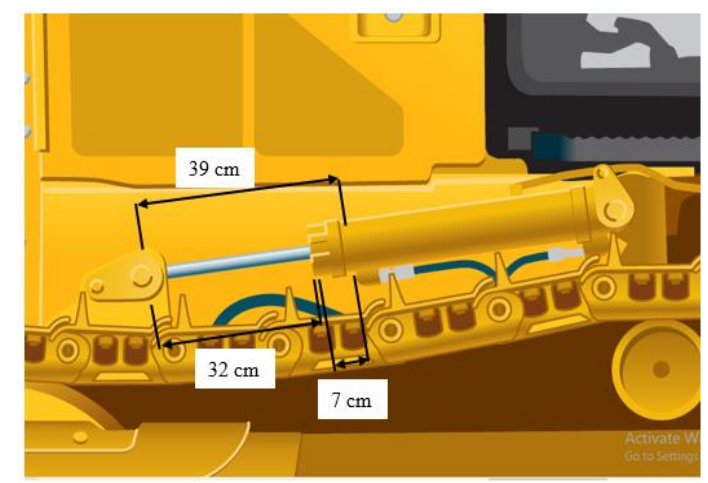

Gambar 2. Pengambilan data pada cylinder rod Sumber: Data penelitian, 2021

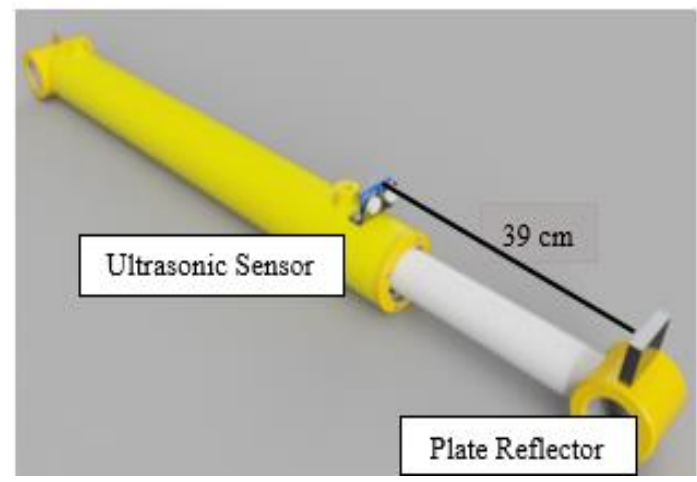

Gambar 3. Penempatan ultrasonic sensor Sumber: Data penelitian, 2021

Kemudian penempatan posisi dari gyroscope \& accelerometer sensor yang digunakan untuk pembacaan Blade Maximum Either Side Angle dan Blade Cutting Ditch Angle ditempatkan pada bagian tengah atas pada blade yang ada pada Track Type Tractor D3K. Hal ini ditujukan agar pembacaan dari posisi Maximum Either Side Angle dan Cutting Ditches Angle menjadi lebih akurat.

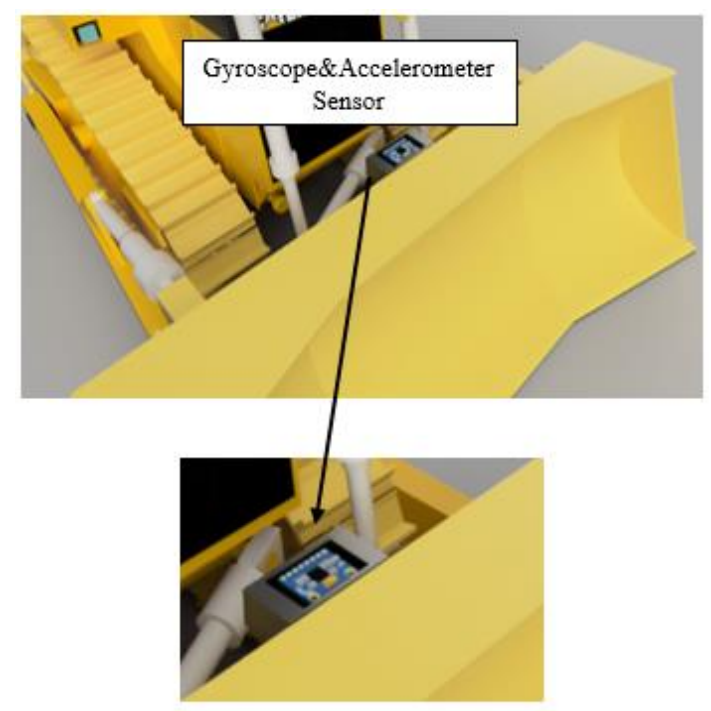

Gambar 4. Penempatan Gyro \& Accelerometer Sensor Sumber: Data penelitian, 2021

Rangkaian dari komponen mikrokontroler yang digunakan sebagai bagian dari rancangan dalam pembuatan Grade Monitoring Assist ini terdiri dari beberapa komponen diantaranya Arduino Atmega328, Ultrasonic Sensor, Gyroscope \& Accelerometer Sensor, LCD, Buzzer, Stepdown, Switch, Rotary Encorder, dan Battery, ditampilkan melalui rangkaian pada Gambar 5. 


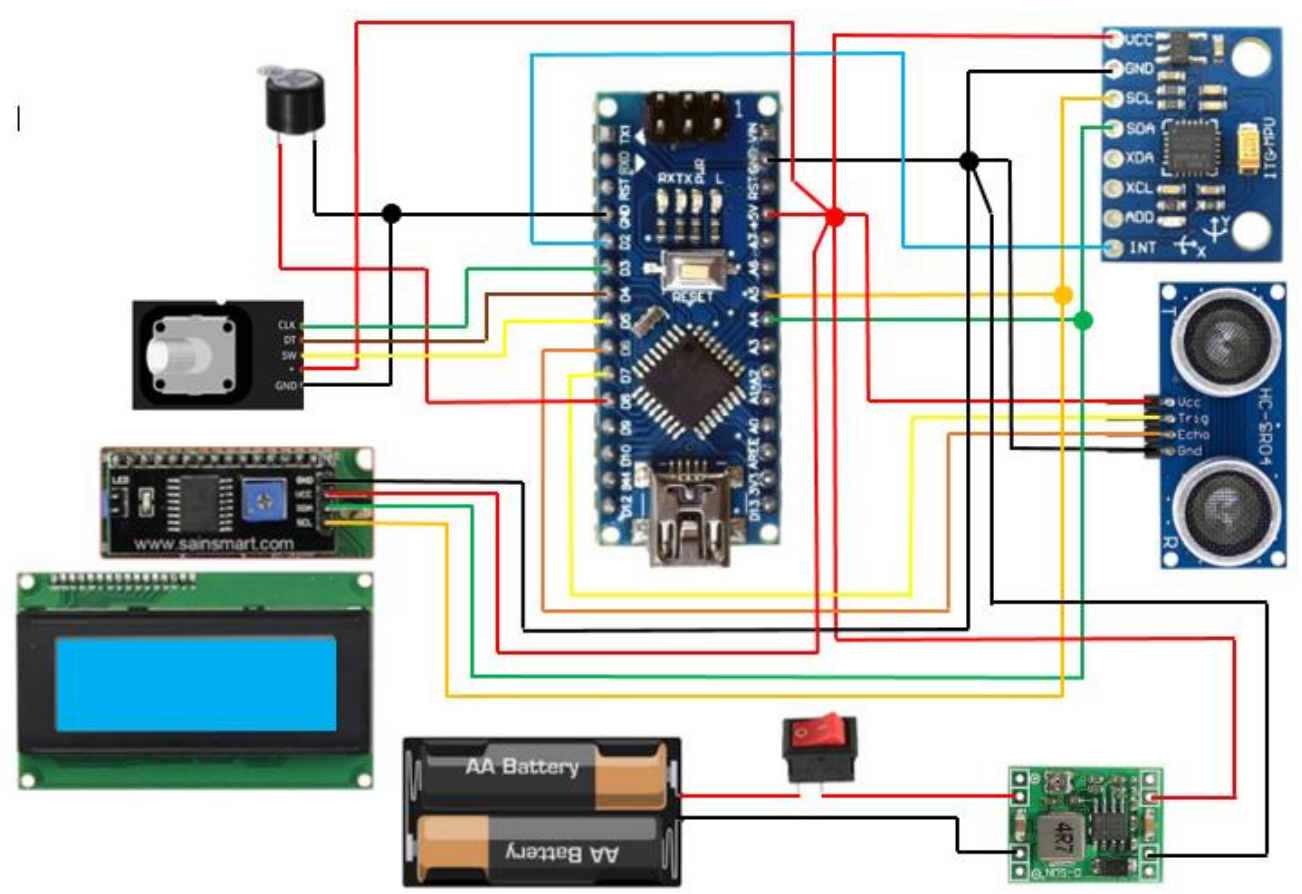

Gambar 6. Rangkaian komponen Mikrokontroler Sumber: Data penelitian, 2021

\section{Hasil dan Pembahasan}

Hasil pengujian alat melalui perbandingan pengujian kinerja alat dengan pengukuran menggunakan alat bantu lain, untuk menilai keakuratan dari pembacaan alat yang dibuat. Pengukuran dilakukan berulang hingga beberapa kali percobaan untuk mengetahui perbandingan hasil perhitungan penggunaan alat Grade Monitoring Assist dengan pengukuran manual dengan tools dan bantuan software derajat yang ditentukan dan akan dihitung tingkat akurasi dari alat.

Perbandingan menggunakan kelipatan kenaikan blade setiap $10 \mathrm{~cm}$ dari tanah hingga nilai kenaikan maksimal sesuai spesifikasi sebagai acuan dari alat untuk mengetahui presentasi error dan presentasi akurasi pada alat. Data ditampilkan pada Tabel 1 dan Tabel 2.

Tabel 1. Pengukuran ketinggian blade

\begin{tabular}{|c|c|c|c|c|c|c|c|c|c|}
\hline \multirow{3}{*}{ No. } & \multirow{3}{*}{$\begin{array}{c}\text { Ukuran } \\
\text { Sebenarnya } \\
(\mathrm{cm})\end{array}$} & \multirow{2}{*}{\multicolumn{5}{|c|}{ Hasil Pembacaan Alat $(\mathrm{cm})$}} & \multirow{3}{*}{$\begin{array}{l}\text { Rata-rata } \\
(\mathrm{cm})\end{array}$} & \multirow{3}{*}{$\begin{array}{c}\text { Error } \\
\%\end{array}$} & \multirow{3}{*}{$\underset{\%}{\text { Akurasi }}$} \\
\hline & & & & & & & & & \\
\hline & & I & II & III & IV & $\mathrm{V}$ & & & \\
\hline 1. & 10 & 12 & 11 & 10 & 11 & 12 & 11 & $10 \%$ & $90 \%$ \\
\hline 2. & 20 & 19 & 20 & 20 & 21 & 21 & 20,2 & $1 \%$ & $99 \%$ \\
\hline 3. & 30 & 31 & 31 & 30 & 31 & 30 & 30,6 & $2 \%$ & $98 \%$ \\
\hline 4. & 40 & 42 & 41 & 41 & 40 & 41 & 41 & $2,50 \%$ & $97,50 \%$ \\
\hline 5. & 50 & 51 & 51 & 50 & 51 & 52 & 51 & $2 \%$ & $98 \%$ \\
\hline 6. & 60 & 62 & 60 & 60 & 61 & 61 & 60,8 & $1,40 \%$ & $98,60 \%$ \\
\hline 7. & 70 & 72 & 70 & 71 & 70 & 71 & 70,8 & $1,20 \%$ & $98,80 \%$ \\
\hline 8. & 75 & 76 & 76 & 76 & 75 & 77 & 76 & $1,40 \%$ & $98,60 \%$ \\
\hline \multicolumn{8}{|c|}{ Rata-rata } & $2,70 \%$ & $97,30 \%$ \\
\hline
\end{tabular}

Sumber: Data penelitian, 2021

Berdasarkan Tabel 2 menunjukkan hasil pengujian pergerakan posisi naik blade dengan pergerakan nilai mulai dari $10 \mathrm{~cm}$ hingga $75 \mathrm{~cm}$ dengan selisih setiap kenaikan nilai 10 mendapatkan nilai akurasi $97,30 \%$ dan error $2,70 \%$. 
Tabel 2. Penggukuran kedalaman blade

\begin{tabular}{ccccccccccc}
\hline & $\begin{array}{c}\text { Ukuran } \\
\text { No }\end{array} \begin{array}{c}\text { Sebenarnya } \\
(\mathrm{cm})\end{array}$ & I & II & III & IV & V & $\begin{array}{c}\text { Rata- rata } \\
(\mathrm{cm})\end{array}$ & $\begin{array}{c}\text { Error } \\
\%\end{array}$ & $\begin{array}{c}\text { Akurasi } \\
\%\end{array}$ \\
\hline 1 & 10 & 12 & 11 & 10 & 12 & 11 & 11 & $10 \%$ & $90 \%$ \\
2 & 20 & 22 & 20 & 20 & 21 & 21 & 20,8 & $1 \%$ & $99 \%$ \\
3 & 30 & 31 & 31 & 32 & 31 & 30 & 31 & $3.4 \%$ & $96.6 \%$ \\
4 & 40 & 42 & 41 & 41 & 40 & 41 & 41 & $2,50 \%$ & $97,50 \%$ \\
5 & 50 & 51 & 51 & 50 & 51 & 52 & 51 & $2 \%$ & $98 \%$ \\
6 & 54 & 55 & 55 & 56 & 54 & 55 & 55 & $1,90 \%$ & $98,10 \%$ \\
\hline \multicolumn{10}{c}{ Rata-rata } \\
\hline
\end{tabular}

Sumber: Data penelitian, 2021

Berdasarkan Tabel 2 menunjukkan hasil pergerakan posisi turun blade dengan pergerakan nilai mulai dari $10 \mathrm{~cm}$ hingga $54 \mathrm{~cm}$ dengan selisih setiap kenaikan nilai 10 mendapatkan nilai akurasi 96,50\% dan error $2,50 \%$.

Untuk hasil pengujian pergerakan up and down blade yang dilakukan untuk mengetahui keakuratan dari hasil pembacaan yang dilakukan oleh alat Grade Monitoring Assist. Pada tahap pengujian ini dilakukan pengujian untuk pergerakan posisi blade maximum angle (either side), cutting ditches (angle $\mathrm{V}$ ) dan pitch saat operator menggerakkan implement. Pengujian ini dilakukan dengan cara membandingkan hasil pengukuran manual dan dengan mengukur menggunakan alat Grade Monitoring Assist. Alat pembanding yang digunakan dalam pengukuran lainnya yaitu aplikasi waterpass. Data ditampilkan pada Tabel 3 dan Tabel 4.

Tabel 3. Hasil pengukuran sudut maximum angle (either side)

\begin{tabular}{|c|c|c|c|c|c|c|c|c|}
\hline \multirow{2}{*}{ No. } & \multirow{2}{*}{$\begin{array}{c}\text { Ukuran Sebenarnya } \\
\left({ }^{\circ}\right)\end{array}$} & \multicolumn{5}{|c|}{ Hasil Pembacaan Alat $\left({ }^{\circ}\right)$} & \multirow{2}{*}{$\begin{array}{l}\text { Rata-rata } \\
\left({ }^{\circ}\right)\end{array}$} & \multirow{2}{*}{$\begin{array}{c}\text { Error } \\
\left({ }^{\circ}\right)\end{array}$} \\
\hline & & $\mathrm{I}$ & II & III & IV & $\mathrm{V}$ & & \\
\hline 1. & $5^{\circ}$ & $6^{\circ}$ & $7^{\circ}$ & $6^{\circ}$ & $6^{\circ}$ & $7^{\circ}$ & $6,4^{\circ}$ & $1,4^{\circ}$ \\
\hline 2. & $10^{\circ}$ & $11^{\circ}$ & $11^{\circ}$ & $12^{\circ}$ & $12^{\circ}$ & $11^{\circ}$ & $11,4^{\circ}$ & $1,4^{\circ}$ \\
\hline 3. & $15^{\circ}$ & $16^{\circ}$ & $16^{\circ}$ & $17^{\circ}$ & $16^{\circ}$ & $17^{\circ}$ & $16,4^{\circ}$ & $1,4^{\circ}$ \\
\hline 4. & $20^{\circ}$ & $21^{\circ}$ & $22^{\circ}$ & $22^{\circ}$ & $22^{\circ}$ & $21^{\circ}$ & $21,6^{\circ}$ & $1,6^{\circ}$ \\
\hline 5. & $25^{\circ}$ & $26^{\circ}$ & $26^{\circ}$ & $27^{\circ}$ & $27^{\circ}$ & $27^{\circ}$ & $26,6^{\circ}$ & $1,6^{\circ}$ \\
\hline \multicolumn{8}{|c|}{ Jumlah rata-rata } & $1,48^{\circ}$ \\
\hline
\end{tabular}

Berdasarkan Tabel 3 menunjukkan hasil pengujian dengan menggerakan blade sesuai sudut pergerakkan implement pada posisi blade maximum angle (either side), cutting ditches (angle $\mathrm{V}$ ), dan pitch. Untuk blade maximum angle (either side) perbandingan hasil pembacaan pergerakan nilai sudut mulai dari sudut $5^{\circ}$ hingga kelipatan 5 dari nilai sudut awal yang ditentukan, dengan selisih setiap kenaikan nilai $5^{\circ}$ mendapatkan nilai error rata-rata dari alat Grade Monitoring Assist 1,48 .

Tabel 4. Hasil pengukuran sudut Cutting Ditches (Angle V)

\begin{tabular}{|c|c|c|c|c|c|c|c|c|}
\hline \multirow{2}{*}{ No. } & \multirow{2}{*}{ Ukuran Sebenarnya $\left(^{\circ}\right)$} & \multicolumn{5}{|c|}{ Hasil Pembacaan Alat $\left(^{\circ}\right)$} & \multirow{2}{*}{$\begin{array}{c}\text { Rata-rata } \\
\left({ }^{\circ}\right)\end{array}$} & \multirow{2}{*}{$\begin{array}{c}\text { Error } \\
\left({ }^{\circ}\right)\end{array}$} \\
\hline & & $\mathrm{I}$ & II & III & IV & $\mathrm{V}$ & & \\
\hline 1. & $0^{\circ}$ & $0,7^{\circ}$ & $0,6^{\circ}$ & $0,7^{\circ}$ & $0,7^{\circ}$ & $0,8^{\circ}$ & $0,7^{\circ}$ & $0,7^{\circ}$ \\
\hline 2. & $1^{\circ}$ & $1,6^{\circ}$ & $1,7^{\circ}$ & $1,6^{\circ}$ & $1,6^{\circ}$ & $1,7^{\circ}$ & $1,64^{\circ}$ & $0,64^{\circ}$ \\
\hline 3. & $2^{\circ}$ & $2,4^{\circ}$ & $2,7^{\circ}$ & $2,6^{\circ}$ & $2,7^{\circ}$ & $2,7^{\circ}$ & $2,62^{\circ}$ & $0,62^{\circ}$ \\
\hline 4. & $3^{\circ}$ & $3,4^{\circ}$ & $3,6^{\circ}$ & $3,7^{\circ}$ & $3,8^{\circ}$ & $3,6^{\circ}$ & $3,62^{\circ}$ & $0,62^{\circ}$ \\
\hline 5. & $4^{\circ}$ & $4,7^{\circ}$ & $4,6^{\circ}$ & $4,7^{\circ}$ & $4,7^{\circ}$ & $4,8^{\circ}$ & $4,7^{\circ}$ & $0,7^{\circ}$ \\
\hline 6. & $5^{\circ}$ & $5,6^{\circ}$ & $5,6^{\circ}$ & $5,7^{\circ}$ & $5,7^{\circ}$ & $5,6^{\circ}$ & $5,64^{\circ}$ & $0,64^{\circ}$ \\
\hline 7. & $6^{\circ}$ & $6,7^{\circ}$ & $6,8^{\circ}$ & $6,8^{\circ}$ & $6,7^{\circ}$ & $6,7^{\circ}$ & $6,74^{\circ}$ & $0,74^{\circ}$ \\
\hline 8. & $7^{\circ}$ & $7,8^{\circ}$ & $7,5^{\circ}$ & $7,5^{\circ}$ & $7,8^{\circ}$ & $7,7^{\circ}$ & $7,66^{\circ}$ & $0,66^{\circ}$ \\
\hline \multicolumn{8}{|c|}{ Jumlah rata-rata } & $0,66^{\circ}$ \\
\hline
\end{tabular}

Sumber: Data penelitian, 2021

Berdasarkan Tabel 4 menunjukkan hasil pengukuran untuk cutting ditches (angle V) perbandingan hasil pembacaan pergerakan nilai sudut mulai dari sudut $0^{\circ}$ hingga posisi $7^{\circ}$, dengan selisih setiap kenaikan sudut $1^{\circ}$ maka didapatkan nilai error rata-rata dari alat Grade Monitoring Assist $0,665^{\circ}$. 


\section{Kesimpulan}

Dari penelitian ini dapat disimpulkan bahwa alat Grade Monitoring Assist dapat menggunakan power source berupa 2 buah battery 18650 yang dirangkai secara seri. Unit dapat dipasang alat Grade Monitoring Assist tanpa mengganggu sistem lain atau mengubah sistem pada unit. Alat Grade Monitoring Assist dapat melakukan kalibrasi secara otomatis sebelum alat dinyalakan untuk memastikan alat yang baru dinyalakan memulai perhitungan mulai dari posisi yang ditentukan pada saat alat dipasang.

Sistem peringatan (warning) berupa bunyi buzzer dan nyala lampu LED yang dimaksudkan pada saat nilai parameter melewati atau tidak sesuai dengan nilai yang sebelumnya diset-up sebelum dilakukan pengoperasian unit. Untuk melindungi module dari debu atau kotoran digunakan case yang cukup melindung bagian hardware module, selain itu kabel juga telah dilindungi oleh cable manager untuk melindungi dari kotoran dabu seta agar kabel terlihat lebih rapi. Alat dapat dilakukan pemasangan dengan mudah karena dapat langsung ditempelkan pada bagian yang telah ditentukan, untuk case yang menggunakan magnet sebagai sarana pemasangannya seperti case display dan gyro serta accelerometer sensor. Atau dapat dikencangkan bagi case yang menggunakan belt sebagai saran pemasangannya seperti case ultrasonic sensor. Baterai yang digunakan pada alat Grade Monitoring Assist cukup mampu untuk digunakan karena dapat bertahan cukup lama yaitu 25 jam lebih menurut perhitungan.

\section{Referensi}

[1] Satriawan, N. Budi, "Optimalisasi produktivitas dan kinerja alat berat dengan analisa data real time parameter," Prosiding Temu Profesi Tahunan XXVIII Perhapi, 2019.

[2] GNSS Antennas for Construction, SITECH-products. "Increase Productivity with The Latest Positioning Technology," Product Catalog. Uni Emirate Arab. November 2017

[3] Asia Pasific Learning, "Earthmoving Concept," PT Trakindo Utama. Bogor. Departement Training Center. 2013.

[4] K. Hayashi, K. Shimada, E. Ishibashi, K. Okamoto, and Y. Yozenewa, "Development of D61EXi/PXi-23: Bulldozer with automatic control system of work equipment," Komatsu Technical Report, vol. 59 (166), pp. 1-8, 2013.

[5] Q. Song, W. J. Wang, C. Jia, Y. L. Yao, and S. B. Wang, "Research on fuel consumption of hybrid bulldozer under typical duty cycle," In: Mechanical Engineering and Control Systems: Proceedings of 2015 International Conference on Mechanical Engineering and Control Systems (MECS2015). Pp. 54-57, 2016.

[6] A. Bulgakov, S. Emelianov, T. Bock, \& G. Tokmakov, "Adaptive control of bulldozer's workflows," In ISARC. Proceedings of the International Symposium on Automation and Robotics in Construction, Vol. 33, pp, IAARC Publications, 2016.

[7] M. S. Korytov, V. S. Shcherbakov, and V. V. Titenko, "Effect of the angles of the earth-moving machine moldboard on the cross slope of the graded surface," In Journal of Physics: Conference Series, Vol. 1210, No. 1, pp. 012070, IOP Publishing, 2019.

[8] G. Bobby, E. Susanto, and FY Supratman, "Implementasi Robot Keseimbangan Beroda Dua Berbasis Mikrokontroler," J. ELKOMIKA, vol. 3 (2), pp. 2338-8323, 2015.

[9] R. Bimarta, A.E. Putra, and A. Dharmawan, "Balancing Robot Menggunakan Metode Kendali Proporsional Integral Derivatif," IJEIS Indones. J. Electron. Instrum. Syst, vol. 5, no. 1, pp. 89, 2015.

[10] M. Junaedi, "Balancing Robot Beroda Dua Dengan Menggunakan Sensor Gyroscope Berbasis Arduino Uno (Doctoral dissertation, Universitas Mataram), 2018.

[11] R. Bimarta, A Eko Putra, dan A. Dharmawan, "Balancing robot menggunakan metode kendali proporsional integral derivatif," J. IJELIS, vol. 5 (1), hal. 2088-3714, 2015.

[12] L.Y. Priyoprahastyo, A. Rusdinar, and E. Susanto, "Design and Implementation of Collision Avoidance for Automated Guided Vehicle (AGV) Using Ultrasonic Sensors with Fuzzy Logic Methods," e-Proceeding of Engineering, vol. 2 (2), p. 1995, 2015.

[13] I. Waldy, A. Rusdinar, and E. Estananto, "Design and Implementation System Automatic Guided Vehicle (AGV) Using RFID for Position Information," Journal of Measurements, Electronics, Communications, and Systems, vo. 1, no. 1, D1-6, 2015. 
[14] L. Y. A. Priyoprahasto, A. Rusdinar, and E. Susanto, "Perancangan Dan Implementasi Sistem Pencegah Tabrakan Pada Automated Guided Vehicle (AGV) Menggunakan Sensor Ultrasonik Dengan Metode Logika Fuzzy," Proceedings of Engineering, vol. 2, no. 2, 2015.

[15] E. Aprilian, "Pengembangan Sistem Pendaratan Otomatis Pada Pesawat Tanpa Awak. Fakultas Teknologi Industri," Tugas Akhir, Jurusan Elektro, Institut Teknologi Sepuluh November, Surabaya. 2017. 